\title{
Retraction Note to: Study on Methylation of Naphthalene with Methanol over ZSM-5 (core)/SAPO-11(shell) Composite Molecular Sieve Alcohols
}

\author{
Xiaoxiao Wang $a$, Fang Guo ${ }^{b}$, Xianxian Weic, Zhenmin Liu ${ }^{a}$, Yingchun Wang $a$, \\ Shaoqing Guo ${ }^{c, *}$ Yuanyang Wanga,**, and Yue Yud \\ a Taiyuan University of Science and Technology, School of Chemical and Biological Engineering, Taiyuan, 030024 China \\ ${ }^{b}$ Jin Zhong University, College of Chemistry and Chemical Engineering, Yuci, 030619 China \\ c Taiyuan University of Science and Technology, College of Environment and Safety, Taiyuan, 030024 China \\ ${ }^{d}$ Lin Yi Academy of Technology Cooperation and Application, Linyi, 276000 China \\ e-mail:*guosq@sxicc.ac.cn,**yywangs@163.com
}

DOI: $10.1134 / \mathrm{S} 1070427219100173$

The article is retracted by the Editor-in-Chief since it was submitted to two different journals with the copyright transfer agreements signed by the authors on the same day for both journals. The authors did not explain why this happened. Eventually the article was published in two journals: Russian Journal of Applied Chemistry, 2018, Volume 91, Issue 6, pp. 1002-1008 with DOI https://doi.org/10.1134/S1070427218060198 and Russian Journal of Physical Chemistry A, 2019, Volume 93, Issue 3, pp. 431-436 with DOI https://doi.org/10.1134/S0036024419030269. 